\title{
Heterologous expression and mutagenesis of recombinant Vespa affinis hyaluronidase protein (rVesA2)
}

\author{
Prapenpuksiri Rungsa ${ }^{1,2}$, Piyapon Janpan ${ }^{1,2}$, Yutthakan Saengkun ${ }^{1,2}$, Nisachon Jangpromma ${ }^{1} \mathbb{D}$, Sompong \\ Klaynongsruang ${ }^{1}\left(\mathbb{D}\right.$, Rina Patramanon $^{1} \mathbb{1}^{\mathbb{D}}$, Nunthawun Uawonggul ${ }^{3}$, Jureerut Daduang ${ }^{4}$ (D), Sakda Daduang ${ }^{1,2, *}$ \\ ${ }^{1}$ Protein and Proteomics Research Center for Commercial and Industrial Purposes (ProCCl), Department of Biochemistry, Faculty of Science, Khon Kaen \\ University, Khon Kaen 40002, Thailand. \\ ${ }^{2}$ Division of Pharmacognosy and Toxicology, Faculty of Pharmaceutical Sciences, Khon Kaen University, Khon Kaen 40002 , Thailand. \\ ${ }^{3}$ Faculty of Science, Nakhon Phanom University, Nakhon Phanom, 48000, Thailand. \\ ${ }^{4}$ Centre for Research and Development of Medical Diagnostic Laboratories, Faculty of Associated Medical Sciences, Khon Kaen University, Khon Kaen, \\ Thailand.
}

\section{Keywords: \\ Vespa affinis \\ Hyaluronidase \\ Wasp \\ Venom}

Structure analysis

Modelling

Cloning

Protein expression

\begin{abstract}
Background: Crude venom of the banded tiger wasp Vespa affinis contains a variety of enzymes including hyaluronidases, commonly known as spreading factors.

Methods: The cDNA cloning, sequence analysis and structural modelling of $V$. affinis venom hyaluronidase (VesA2) were herein described. Moreover, heterologous expression and mutagenesis of rVesA2 were performed.

Results: V. affinis venom hyaluronidase full sequence is composed of 331 amino acids, with four predicted $\mathrm{N}$-glycosylation sites. It was classified into the glycoside hydrolase family 56 . The homology modelling exhibited a central core $(\alpha / \beta)_{7}$ composed of Asp107 and Glu109, acting as the catalytic residues. The recombinant protein was successfully expressed in E. coli with hyaluronidase activity. A recombinant mutant type with the double point mutation, Asp107Asn and Glu109Gln, completely lost this activity. The hyaluronidase from crude venom exhibited activity from $\mathrm{pH} 2$ to 7 . The recombinant wild type showed its maximal activity at $\mathrm{pH} 2$ but decreased rapidly to nearly zero at $\mathrm{pH} 3$ and was completely lost at $\mathrm{pH} 4$.

Conclusion: The recombinant wild-type protein showed its maximal activity at $\mathrm{pH} 2$, more acidic $\mathrm{pH}$ than that found in the crude venom. The glycosylation was predicted to be responsible for the $\mathrm{pH}$ optimum and thermal stability of the enzymes activity.
\end{abstract}

\footnotetext{
* Correspondence: sakdad@kku.ac.th http://dx.doi.org/10.1590/1678-9199-JVATITD-2019-0030 Received: 21 May 2019; Accepted: 18 October 2019; Published online: 05 December 2019
} 


\section{Background}

Hyaluronidase is an enzyme family that catalyze the hydrolysis of hyaluronic acid (HA) and several other glycosaminoglycan constituents of the extracellular matrix of vertebrates. It is often found in all types of animal venom [1, 2, 3]. Venom toxin cocktails comprise high-molecular weight molecules, such as phospholipases A (PLA), hyaluronidases, antigen 5 and acid phosphatase, low-molecular weight compounds and peptides such as hemolytic peptides, antimicrobial peptides, and amines $[4,5,6,7,8]$. In animal venoms, hyaluronidases degrade hyaluronic acids in extracellular matrix and are generally referred to as "spreading factors" that enhance envenomation by increasing the absorption and diffusion rate of systemic venom toxins in the circulation of prey [9]. Venom hyaluronidases have also been identified as major allergens of scorpions, bees, hornets and wasps, which can induce serious and occasionally fatal systemic IgE-mediated anaphylactic reactions in humans $[1,10-12]$. Several studies have reported the purification and characterization of venom hyaluronidases from spider [13, $14]$, scorpion $[15,16]$, conus [17], snake [18, 19, 20], freshwater stingray [9] and wasp [21].

The hyaluronidase from Hymenoptera venom is relatively conserved. Hymenoptera stings represent one of the three major causes of anaphylaxis worldwide [5], including serious symptoms after envenomation [22, 23]. Vespa affinis, the tiger wasp, are mostly found in the Asia-Pacific region, including Thailand. The nests of $V$. affinis are typically located in the trees of forests near human habitats, which results in a record-breaking number of stinging accidents every year [24].

The venom of $V$. affinis is lethal. Sukprasert et al. [25] reported a paralytic dose $\left(\mathrm{PD}_{50}\right)$ of approximately $12.2 \mu \mathrm{g} / \mathrm{g}$ of body weight in crickets (Gryllus sp.). The major venom allergen proteins are PLA, with $100 \%$ allergenicity, and hyaluronidase, with 53.3\% allergenicity [24]. Additionally, the proteomic analysis of $V$. affinis venom performed by Rungsa et al. [26] detected venom hyaluronidases, which are major venom proteins. Antihyaluronidase serum inhibited or delayed the occurrence of large tissue damage, potentially allowing a more efficient clinical management of the victim [27, 28].

In the present study, the cDNA encoding $V$. affinis hyaluronidase was sequenced. The amino acid sequences were also deduced. The in silico prediction of its higher-level protein structures was performed. A mutant type with amino acid substitutions at the catalytic site was produced to elucidate their functions. The activity of recombinant mutant type was comparatively characterized in relation to that of the wild-type protein.

\section{Methods}

\section{Materials}

The worker wasp V. affinis was obtained from Nakornphanom Province, Thailand. The venom glands were dissected and kept at $-80^{\circ} \mathrm{C}$. The bacterial strains and the ImPromII Reverse
Transcription System kit was acquired from Invitrogen Life Technologies (USA). We purchased the pET32a expression plasmid from Novagen (USA).

The present study was approved by the Animal Ethics Committee of Khon Kaen University based on the Ethics for Animal Experimentation of the National Research Council of Thailand (Reference. 0514.1.12.2/1).

\section{Protein biochemistry}

One-dimensional polyacrylamide gel electrophoresis was performed following standard methods, using 13\% (w/v) separating gels and $4 \%(\mathrm{w} / \mathrm{v})$ stacking gels. The low molecularweight marker (GE Healthcare, USA) was used as the protein standard. The gel was separated at 150 volts for $80 \mathrm{~min}$. After separation, the gel was stained with Coomassie blue R-250 staining solution. The protein band was excised from the $13 \%$ SDS-PAGE gel. An in-gel digestion was performed according to the previous description from Rungsa et al. [29]. The gel was digested using trypsin solution (20 ng trypsin in 50\% ACN/10\% ammonium bicarbonate) following a standard method described by the Research Instrument Center, Khon Kaen University, Thailand. The sample was analyzed with a nano-LC (EasynLC II, Bruker Daltonics, USA) coupled to an ion trap mass spectrometer (Amazon Speed ETD, Bruker, USA) equipped with an ESI nanosprayer. LC-MS/MS spectra were analyzed using Compass Data Analysis v. 4.0. Compound lists were exported as Mascot generic files (mgf) for further analysis in the Mascot program [26].

\section{Cloning and isolation of CDNA encoding V. affinis hyaluronidase using PCR techniques}

Total RNA was extracted from the $V$. affinis venom gland using TRIzol $^{\oplus}$ reagent (Invitrogen Life Technologies, USA). Firststrand DNA synthesis was performed using a RevertAid First stand cDNA synthesis Kit (Thermo Scientific, USA) following the manufacturer's instructions for the PCR amplification of encoded sequences. The amplification of hyaluronidase genes was performed using master mix reagent kits with Taq DNA polymerase (Vivantis, Malaysia). The primers were described by Rungsa et al. [27, 30]. The 3'rapid amplification of cDNA ends (3'RACE) was carried out according to the kit's instruction manual (Invitrogen Life Technologies, USA) using gene-specific primers and AUAP universal primers. The PCR products were purified using GenepHlow Gel Extraction kits (Geneaid, Taiwan) and cloned into a PGEM $^{\circledR}$-T easy vector (Promega, USA) for sequencing [29, 31].

\section{Sequence alignments, the prediction of secondary structure and homology modelling}

The $V$. affinis hyaluronidase sequence (VesA2) was analyzed using FinchTV and BLAST (http://www.ncbi.nlm.nih.gov/ BLAST/), and a multisequence alignment was carried out using Multiple Sequence Alignment Clustal Omega (https:// www.ebi.ac.uk/Tools/msa/clustalo). The ExPasy tool was used 
to translate the sequence (https://web.expasy.org/translate/). The protein sequence was examined with the SWISS-MODEL for three-dimensional structure prediction. The structure was investigated with the PDB viewer program (PDB; http:// swissmodel.expasy.org/) and Chimera software (https://www.cgl. ucsf.edu/chimera/download.html). The stereochemical quality validation of the model was confirmed using Ramachandran plot. The $N$-glycosylation prediction was performed using the CBS prediction severs (http://www.cbs.dtu.dk/services/NetNGlyc/). The free web server DiANNA (http://clavius.bc.edu/ clotelab/ DiANNA/) was used to predict the formation of disulfide bonds.

\section{Cloning and expression of the recombinant gene in E. coli}

The wild-type $V$. affinis hyaluronidase was amplified by polymerase chain reaction (PCR). The forward and reverse primers contained Kpn I and Not I restriction sites, respectively. The PCR-amplified products were sequentially subjected to $1.2 \%$ agarose gel electrophoresis, double digestion with Kpn I/Not I restriction enzymes and cloning into a pre-digested pET32a expression vector following the manufacturer's instructions. The constructs were transformed into Escherichia coli BL-21 (DE3) chemically competent cells, plated on Luria Bertani (LB) agar plates containing ampicillin and incubated at $37^{\circ} \mathrm{C}$ overnight. The colony was verified by colony PCR and analyzed by DNA sequencing using an Automated PCR sequencer (First base, Malaysia) [32].

\section{Site-directed mutagenesis}

Site-directed mutagenesis was carried out using splicing by overlapping extension PCR to create the mutant $V$. affinis hyaluronidase following previous studies [33]. The mature $V$. affinis hyaluronidase in the pGEM-T easy vector was used as the template for mutagenesis. The two sites were chosen for PCR-based site-directed mutagenesis (Table 1). The Pfu DNA polymerase was used for the amplification the recombinant mutant type. The mutant VesA2 was poly-A-tailed by Taq polymerase and cloned into the pGEM-T easy vector. The positive clones were verified by colony PCR. The cDNA encoding hyaluronidase was subcloned into pET32a.

\section{Small-scale expression and optimization of the expression conditions}

The E. coli cells containing the recombinant $V$. affinis hyaluronidase gene (wild-type and mutant) were grown in 5 $\mathrm{mL} \mathrm{LB}$ liquid medium containing $50 \mu \mathrm{g} / \mathrm{mL}$ ampicillin at $37^{\circ} \mathrm{C}$ overnight. A total of $50 \mu \mathrm{L}$ of pre-cultured cells was added to $5 \mathrm{~mL}$ fresh LB liquid medium until the $\mathrm{OD}_{600}$ reached 0.4-0.6. The isopropyl- $\beta$-D-thiogalactopyranoside (IPTG) concentration, induction time and temperature for the expression of foreign proteins in E. coli BL-21(DE3) were optimized. Under 15 and $37^{\circ} \mathrm{C}$, IPTG was added to each fresh subculture $\left(\mathrm{OD}_{600}=0.5\right)$ with different final concentrations $(0,0.1,0.2,0.3,0.4,0.5$,
Table 1. Gene-specific primers that were designed in this study

\begin{tabular}{ll}
\hline F-Kpn I primer & 5'-GGTACCTCCGAGAGACCGAAAAAAG-3' \\
R-Not I primer & 5'-GCGGCCGCAGTTAACGGCTTCTGTCA-3' \\
F-mutant & 5'-GGTATAATCAACTTTCAAAGATGGAGA-3' \\
R-mutant & 5'-TCTCCATCTTTGAAAGTTGATTATACC-3' \\
\hline
\end{tabular}

1 and $1.5 \mathrm{mM}$ ) and was incubated for additional 24 hours for the optimization of the IPTG concentration. For the optimization of the induction time, subcultures were incubated for additional times (non-induction, 4, 6, 8, 10 hours and overnight) with optimal conditions of the IPTG concentration and induction temperature. The temperature induction was performed at various temperatures $\left(15^{\circ} \mathrm{C}\right.$ and $\left.37^{\circ} \mathrm{C}\right)$. All liquid subcultures were collected and then mixed with $2 \mathrm{x}$ solubilizing solution (v/v: 1/1) [0.5 M Tris-HCl, pH 6.8, 10\% (v/v) glycerol, 10\% (w/v) sodium dodecyl sulfate (SDS) and $1 \%(\mathrm{w} / \mathrm{v})$ bromophenol blue] and heated at $100^{\circ} \mathrm{C}$ for $10 \mathrm{~min}$ for analysis using SDS-PAGE to choose the optimal culture parameters.

\section{Up-scale expression and purification of recombinant proteins}

For the up-scale expression of recombinant $V$. affinis hyaluronidase, the optimal expression conditions were used. The recombinant $V$. affinis hyaluronidase was cultured in 10 $\mathrm{mL} \mathrm{LB}$ liquid medium containing $50 \mu \mathrm{g} / \mathrm{mL}$ ampicillin at $37^{\circ} \mathrm{C}$ overnight. Fresh LB liquid medium (1 L) containing $50 \mu \mathrm{g} / \mathrm{mL}$ ampicillin was incubated with $10 \mathrm{~mL}$ overnight culture until the $\mathrm{OD}_{600}$ reached 0.3-0.8, and IPTG was added at the optimized concentration. The E. coli cells were harvested by centrifugation at $5000 \times \mathrm{g}$ for $10 \mathrm{~min}$ at $4^{\circ} \mathrm{C}$, suspended in $30 \mathrm{~mL}$ of lysis buffer

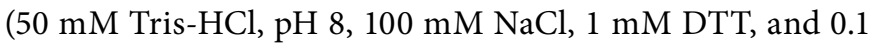
$\mathrm{mg} / \mathrm{mL}$ lysozyme) and lysed.

The recombinant protein was detected in the insoluble fraction. The cell pellet was washed using $20 \mathrm{mM}$ Tris- $\mathrm{HCl}, \mathrm{pH} 8$ and $2 \mathrm{M}$ urea. Then, it was solubilized in $20 \mathrm{mM}$ Tris- $\mathrm{HCl}, \mathrm{pH} 8$ and $1 \mathrm{mM}$ DTT containing $4 \mathrm{M}$ urea with stirring at room temperature for 3 hours. The soluble fraction was collected after centrifugation $(10000 \times \mathrm{g}, 30 \mathrm{~min})$ and kept at $-20^{\circ} \mathrm{C}$ until use. The soluble fraction was dialyzed using reducing urea concentrations $(20 \mathrm{mM}$ Tris- $\mathrm{HCl}, \mathrm{pH} 8,10 \%$ glycerol and $2 \mathrm{M}$ or $0 \mathrm{M}$ urea, respectively). The refolded protein was purified using His-gravitrap column (GE healthcare, USA) following manual instruction in $20 \mathrm{mM}$ Tris- $\mathrm{HCl}, \mathrm{pH} 8$, under a step-wise imidazole concentration. The purified protein was concentrated using Centricon ${ }^{\circledR} 30 \mathrm{kDa}$ filters and used for the enzymatic testing.

\section{Hyaluronidase activity assay}

The zymographic gel hyaluronidase activity assay was performed using 13\% SDS-PAGE containing $0.5 \mathrm{mg} / \mathrm{mL}$ hyaluronic acid (Sigma, USA) as a substrate. The gel was incubated in $3 \%$ Triton X-100 for 1 hour, transferred to the hyaluronidase assay buffer 
(0.15 M NaCl in $0.1 \mathrm{M}$ formate buffer $\mathrm{pH} 3.7)$ for 16 hours. After that, gels were stained in Alcian Blue solution (0.5\% Alcian Blue in $3 \%$ acetic acid) and destained in $7 \%$ acetic acid until the clear band was appeared [34].

A turbidity hyaluronidase activity assay was performed in a reaction mixture containing $100 \mu \mathrm{g}$ crude venom/fraction, $0.5 \mathrm{mg} / \mathrm{mL}$ hyaluronic acid and $0.2 \mathrm{M}$ formate buffer, $\mathrm{pH}$ 3 , containing $0.15 \mathrm{M} \mathrm{NaCl}$ and was incubated for $30 \mathrm{~min}$ at $37^{\circ} \mathrm{C}$. A $2 \%$ cetyltrimethylammonium bromide (CTAB) (w/v) solution containing $2.5 \% \mathrm{NaOH}(\mathrm{w} / \mathrm{v})$ was used to stop the reaction, and the absorbance was measured at $405 \mathrm{~nm}$. One unit of hyaluronidase enzyme activity has been defined as the quantity of the enzyme that reduce the turbidity equal to one unit of international standard preparation after incubating with substrate at $37^{\circ} \mathrm{C}$ for $30 \mathrm{~min}$ at $\mathrm{pH} 4$ [35].

\section{The effect of $\mathrm{pH}$ and temperature on the activity assay}

The optimum $\mathrm{pH}$ of the recombinant enzyme was determined using $50 \mathrm{mM}$ formate buffer ( $\mathrm{pH} 2-4), 50 \mathrm{mM}$ sodium acetate buffer ( $\mathrm{pH}$ 5-6) and $50 \mathrm{mM}$ Tris-HCl buffer ( $\mathrm{pH} 7-10)$. The $\mathrm{pH}$ stability was investigated by preincubating the enzyme at each $\mathrm{pH}$ for $30 \mathrm{~min}$ at $37^{\circ} \mathrm{C}$ and then measuring the residual activities. The optimum temperature was analyzed over a range of $30-80^{\circ} \mathrm{C}$, and the thermostability was investigated by preincubating the enzyme in the absence of substrate for the indicated times at 50 and $60^{\circ} \mathrm{C}$ and then measuring the residual activities [27].

\section{Results}

\section{Sequencing and structural analysis}

The full length of the wild-type $V$. affinis venom hyaluronidase gene (VesA2) was determined with classical strategies, using mRNA from the venom gland as the template. The full nucleotide sequence of VesA2 was $1145 \mathrm{bp}$ in length and had $152 \mathrm{bp}$ in the 3 'untranslated region (3'UTR). The prediction revealed that the primary sequence of the wild-type $V$. affinis hyaluronidase polypeptide (VesA2) contained 331 amino acids (Figure 1). The theoretical average mass was $39.0487 \mathrm{kDa}$ whereas the theoretical isoelectric point (pI) was 9.16. Four potential $N$-glycosylation sites (Asn-Xaa-Thr/Ser, where Xaa is any amino acid residue except proline), Asn79, Asn99, Asn187 and Asn325, and two disulfide bridges, C19-C185 and C197-C308, were predicted. The amino acid residues Asp and Glu, which are commonly found in active sites, usually acting as catalytic residues, were observed at positions 107 and 109, respectively [36].

The generation of a mutant protein with the substitution of Asp107 and Glu109 to Asn107 and Gln109 was carried out with site-directed mutagenesis strategies. Oligonucleotide primers containing the restriction enzyme cutting sites for Kpn I and Not I were synthesized and used for PCR techniques to obtain Asp107Asn and Glu109Gln substitution mutations (Table 1). The mutations were successfully produced. The subsequent nucleotide sequencing, prediction and NCBI-BLAST search confirmed the presence of these substitutions (Figure 2). The predicted amino acid sequences showed high homology to the $V$. affinis hyaluronidase sequences from LC-MS/MS analysis [26].

\section{Multiple sequence alignment and homology modelling}

The wild-type VesA2 sequence alignment showed high homology to active wasp venom hyaluronidase: $96.67 \%$ Vespa tropica (VesT2a), 96.07\% Vespa magnifica (Ves ma2), 90.05\% Dolichovespula maculata (Dol m2), 91.54\% Vespa germanica (Ves g) and $91.23 \%$ Vespula vulgaris (Ves v2a). The wild-type VesA2 showed less homology to those in inactive forms of wasp venom hyaluronidase: $58.61 \%$ Vespula vulgaris (Ves v2b) and 61.93\% VesT2b (Figure 3).

The constructed three-dimensional structure model of VesA2 using the SWISS-MODEL protein homology modelling server was performed based on two templates with structures perfectly clarified from crystallography. Those templates were hyaluronidases from wasp venom ( $V$. valgaris; Ves v 2; 2ATM) (Figure 4) and bee venom hyaluronidase (Apis mellifera; Api m2; 2J88) (data not shown) [36, 37]. The Ves v 2 and Api $m 2$ templates showed 91.23 and $52.74 \%$ sequence identity, respectively, to VesA2. Bee venom hyaluronidase, Api m2, was composed of three parts: hyalurononglucosaminidase A, Fab B and Fab C. VesA2 showed high similarity to the hyalurononglucosaminidase A part [38].

From Ramachandran plot, phi and psi conformation angels of VesA2 backbone for each residues of amino acid were displayed (data not shown). Plot statistics of the model exhibited 90.4\% of the residues in favored regions, $9.3 \%$ in additional allowed regions, $0 \%$ in generously allowed regions and $0.4 \%$ in disallowed regions [39]. VesA2 is composed of seven $\alpha$-helices and seven $\beta$-sheets belonging to the glycoside hydrolase family 56 (E.C. number 3.2.1.35). Figure 4 shows that the position and orientation of the catalytic site and other conserved residues coincide fairly well. The substrate-adjacent residues fell into three regions. The residue contact substrate can be presumed to be involved in binding and substrate recognition. Asp107 and Glu109 are common catalytic residues of Hymenoptera venom hyaluronidase that are found in the active sites. Tyr51, Tyr180, Tyr223 and Typ296 are nearby residues that function proximally to the cleavage point of the substrate and are likely to have been in contact with a transition state and/or the released portion of the cleaved HA chain.

\section{Recombinant wild-type and mutant VesA2 expression}

The mature recombinant VesA2 was subcloned into the pET32a expression vector containing a $6 \mathrm{xHis}$ tag and a thioredoxin fusion at the $\mathrm{N}$-terminus. These tags are useful for recombinant protein expression and solubilization. The peptide mass fingerprints from the LC-MS/MS analysis subsequently searched by Mascot search 


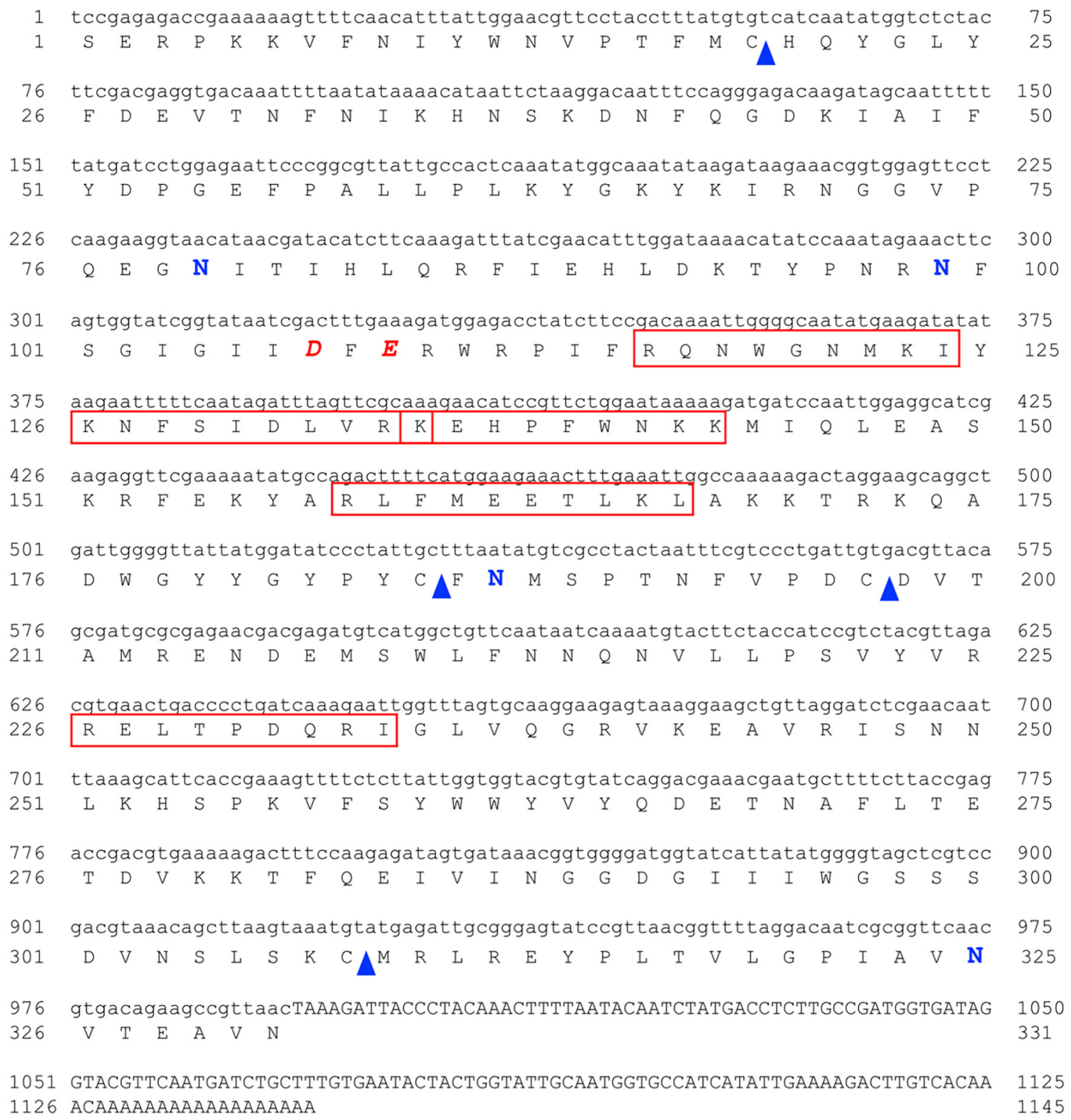

Figure 1. The complete nucleotide and predicted amino acid sequences of Vespa affinis venom hyaluronidase (VesA2). The red italic capital letters ("D" for Asp and "E" for Glu) indicate the catalytic residues of the active sites. Four cysteine residues ("C disulfide bonds. Based on the in silico prediction, the two bonds were C19-C185 and C197-C308. The four predicted N-glycosylation sites (asparagine, "N") are indicated with blue letters. The peptides from the LC-MS/MS analysis are shown in the red boxes.

\section{Nucleotide}

$\begin{array}{llll} & & & \\ \text { Wild-type } & 301 & \text { agtggtatcggtataatcgactttgaagatggagacctatcttccgacaaaattggggcaatatgaagatatat } & 375 \\ \text { DNEQ } & 301 & \text { agtggtatcggtataatcaactttcaaagatggagacctatcttccgacaaaattggggcaatatgaagatatat } & 375\end{array}$

Amino acid

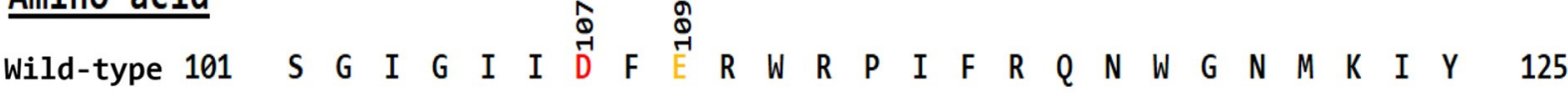

DNEQ $\quad 101$ S $\quad G \quad \begin{array}{lllllllllllllllllllllllll} & & G & I & I & N & F & Q & R & W & R & P & I & F & R & Q & N & W & G & N & M & K & I & Y & 125\end{array}$

Figure 2. The amino acid sequence comparison of wild-type and mutant VesA2. The nucleotide guanine 319 (g319) and guanine 225 (g325) in the wild-type sequence were changed to adenine (a319) and cytosine (c325) in the mutant sequence. These replacements caused the amino acid aspartic acid (Asp $107)$ to change to asparagine (red letters), and glutamic acid (Glu109) changed to glutamine (yellow letters). 


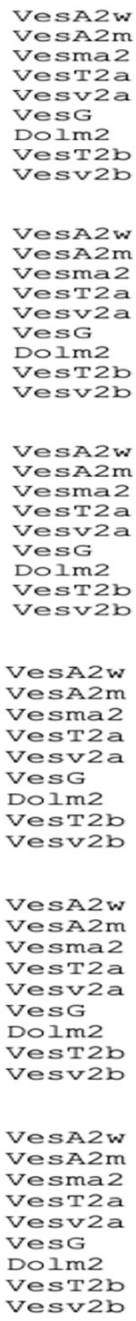

--SERPKKVFNIYWNVPTFMCHQYGLYFDEVTNENIKHNSKDNEQGDKIAIFYDPGEFPA --SERPKKVFNIYWNVPTFMCHQYGLYFDEVTNFNIKHNSKDNFQGDKIAIFYDPGEFPA --SERPKRVFNIYWNVPTFMCHQYGLYFDEVTNFNIKKHNSKDDFOGDKIAIFYDPGEFPA --SERPKRIFNIYWNVPTFMCHQYGLYFEEVTN --SERPKRVFNIYWNVPTFMCHQYDLYFDEVTNFNIKRNSKDDFQGDKIAIFYDPGEFPA --SERPKRVFNIYWNVPTFMCHQYGLYFDEVTNFNIKHNSKDDFQGDKISIFYDPGEFPA NRTNWPKKIFNIYWNVPTYFCHQHGIYFNELTKFDIKYNSKGNYRGETISLFYDPGNFPA DRTIWPKKGFS IYWNI PTHFCHNFGVYFKELKQFNIKYNSMNNFRGETISLFYDPGNFPS

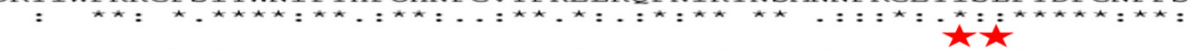
LLPLKYGKYKIRNGGVPQEGNITIHLORFIEHLDKTYPNRNFSGIGI I DFERWRPIFRON LLPLKYGKYKIRNGGV PQEGNITIHLQRFIEHLDKTY PNRNFSGIGI INFORWRPIFRON LIPI KYGKYKIRNGGVPO LISIKDGKYKKRNGGVPOEGNITIHIOKFIENIDKIYPNRNFSGIGVIDFERWRPIFRON LISLKDGKYKKRNGGVPOEGNITIHLQKFIENLDKTYPNRNFSGIGVIDFERWRPIFRON LIPLKEGNYKIRNGGVPQEGNITIHLQRFIENLDKTYPNRNFNGIGVIDFERWRPIFRQN MVPLKNGTYDIRNEGVPQKGNITVHLQQFTKELDEIYPKKISGGIGVINFNKWRPIFRRN MVILKNGTYEIRNEGVPQKGNITIHLEQFTKELDEIYPKKIAGGIGVIHFHNWRPIFRRN

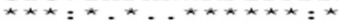

WGNMKIYKNFSIDLVRKEHPFWNKKMIQLEASKRFEKYARLFMEETLKLAKKTRKQADWG WGNMKIYKNESIDIVRKEHPFWNKKMIQIEASKRRFEKYARIFMEETIKLAKKTRKRQADWG WGNMKIYKNFSIDIVRKEHPFWNKKMIELEASKRFEKYARLFMEETLKIAKKTRKQADWG WGNMKIHKNFSIDIVRNEHPTWNKKMIELEASKRFEKYARFFMEETIKIAKKTRKOADWG WGNMKIHKNFSIDLVRNEHPTWNKKMIELEASKRFEKYARFFMEETLKLAKKTRKQADWG WGNMMIHKKFSIDLVRNEHPFWDKKMIELEASKRFEKYARLFMEETLKLAKKTRKQADWG VNNLKINKEVSIDLVRKEHPKWDKSMIEKEASNRFEKSARIFMEKTLKIAKDIRNKNKWG VDNLKINKDISIDLVRKEHPKWDKSMIEKEASNRFETSAKIFMEKTLKIAKEIRKKTEWG

YYGYPYCFNMS PTNFVPDCDVTAMRENDEMSWLFNNONVILPSVYVRRELTPDORIGLVQ YYGYPYCFNMS PTNFVPDCDVTAMRENDEMSWLFNNQNVILPSVYVRREITPDQRIGLVQ YYGYPYCFNMS TNEVPDCDVTARDENNEMSWLFNNONVLLPSVYIRRELTPDORIGLVQ Y YYGYPYC YYGYYCNMSANLVPECDI YHGYPYCPTASTGNPS YHGYPHCLSGSTDKPS FDCDALSMSENDKMSWLFNNQNVLIPSIYLKNVLKPDEKIHLVQ

GRVKEAVRISNNLKHS PKVESYWWYVYQDETNAFLTETDVKKTEQEIVINGGDGIIIWGS GRVKEAVRISNNLKHS PKVFPYWWYVYQDETNAFLTETDVKKTFQEIVINGGDGIIIWGS GRVKEAVRISNNLKHSPKVI GRVKEAVRISNKLKHSPKVESYWWYVYQDETNTELTETDVKKTEQEIVINGGDGIIIWGS GRVKEAVRISNNLKHS PKVFSYWWYVYODETNTELTETDVKRTEOEIVINGGDGIIIWGS GRVKEAVRISNNLKHS PKVLSYWWYVYODETNTELTETDVKKTEQEIVINGGDGIIIWGS GRVKEAVRISNNLKHS PKVLSYWWYVYODETNTYLTETDVKKTEQEIVINGGDGIIIWGS GRVKEAVRISNNLKHS PKVLSYWWYVYQDDTNTFLTETDVKKTEQEIAINGGDGIIIWGS GSVKEAVRISKKFEHLPKVLSYWWYAYEDKMDTFLTETDVKNTF EEILINGGDGIVIWGT

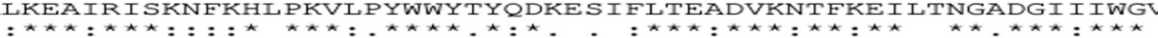

SSDVNSLSKCMRLREYPLTVLGPIAVNVTEAVN------SSDVNSLSKCMRIREYLLTVLGPIAVNVTEAVN------SSDVNSLSKCTRLREYLLTVLGPIAVNVTEAVN------SSDVNSLSKCMRLREYLLTVLGPIAVNVTEAVN------SSDVNSLSKCKRLQDYLLTVLGPIAINVTEAVN-----SSDVNSLSKCKRIQDYLITVLGPIAVNVTEAVN-------

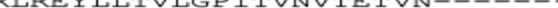
SYELTDRKRCEKLKEYLMKILGPIAFKVTKAVKENTPLNF

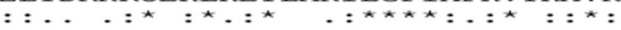

Figure 3. Multiple alignments among the primary sequence of wasp venom hyaluronidases. Stars designate identical residues. Colons and dots indicate similar residues. The catalytic residues ("D" and "E") are indicated with red stars. VesA2w is the wild-type VesA2. VesA2m is the mutant VesA2. Vesma2 (Vespa magnifica), VesT2 (Vespa tropica) Vesv2 (Vespula vulgaris), Dolm2 (Dolichovespula maculata), and VesG (Vespa germanica) are shown. The small "a" and "b" of Vesv2 and VesT2 indicate "active" and "inactive" hyaluronidases, respectively.

of wild-type and mutant type rVesA2 revealed high similarity to the hyaluronidase of $V$. magnifica venom (Table 2).

The expression conditions of the wild-type and mutant rVesA2 for maximal over-expression were the induction with $0.1 \mathrm{mM}$ IPTG at $37^{\circ} \mathrm{C}$ for 4 hours. The wild-type protein exhibited high zymographic gel hyaluronidase activity (Figure 5), whereas the mutant type completely lost this activity (data not shown). The overexpressed protein band from heterologous expression in E. coli was approximately $59 \mathrm{kDa}$ on an SDS denaturing gel, corresponding to a transparent band in the blue background of the zymographic gel of the hyaluronidase activity assay. The size (approximately $59 \mathrm{kDa}$ ) was larger than the theoretical mass $(\sim 39 \mathrm{kDa})$ and was the summation of the VesA2 gene and tags. However, the process of solubility with sonication revealed that the recombinant proteins were insoluble in the aqueous-based buffer commonly known as inclusion bodies (data not shown). The solubility test by SDS-PAGE showed that rVesA2 mainly appeared in the insoluble fraction. To increase the solubility of the recombinant proteins, 4 and $6 \mathrm{M}$ urea were used (Figure 6). After the renaturation of recombinant wild type and mutant type, the hyaluronidase activity was recovered based on an analysis using turbidity hyaluronidase activity assay (Figure $7 \mathrm{~B}$ and Figure $8 \mathrm{~B}$ ). The recovery yields of both recombinant types ranging from 13.0 to $22.5 \mathrm{mg}$ per 1 liter of culture media. During induction, temperature may be a variable. Therefore, the temperature was varied from 15 to $37^{\circ} \mathrm{C}$, and the inclusion bodies remained a problem (data not shown).

\section{Hyaluronidase activity of the wild-type and mutant rVesA2}

A hyaluronidase activity test with a turbidity assay showed that the $V$. affinis venom had activity at $\mathrm{pH}$ ranging from 2 to 10 , with maximal activity at $\mathrm{pH} 6$ (Figure 7A). The recombinant rVesA 2 had activity around $\mathrm{pH} 2$ to 3 , with an optimal $\mathrm{pH}$ at 2 . 


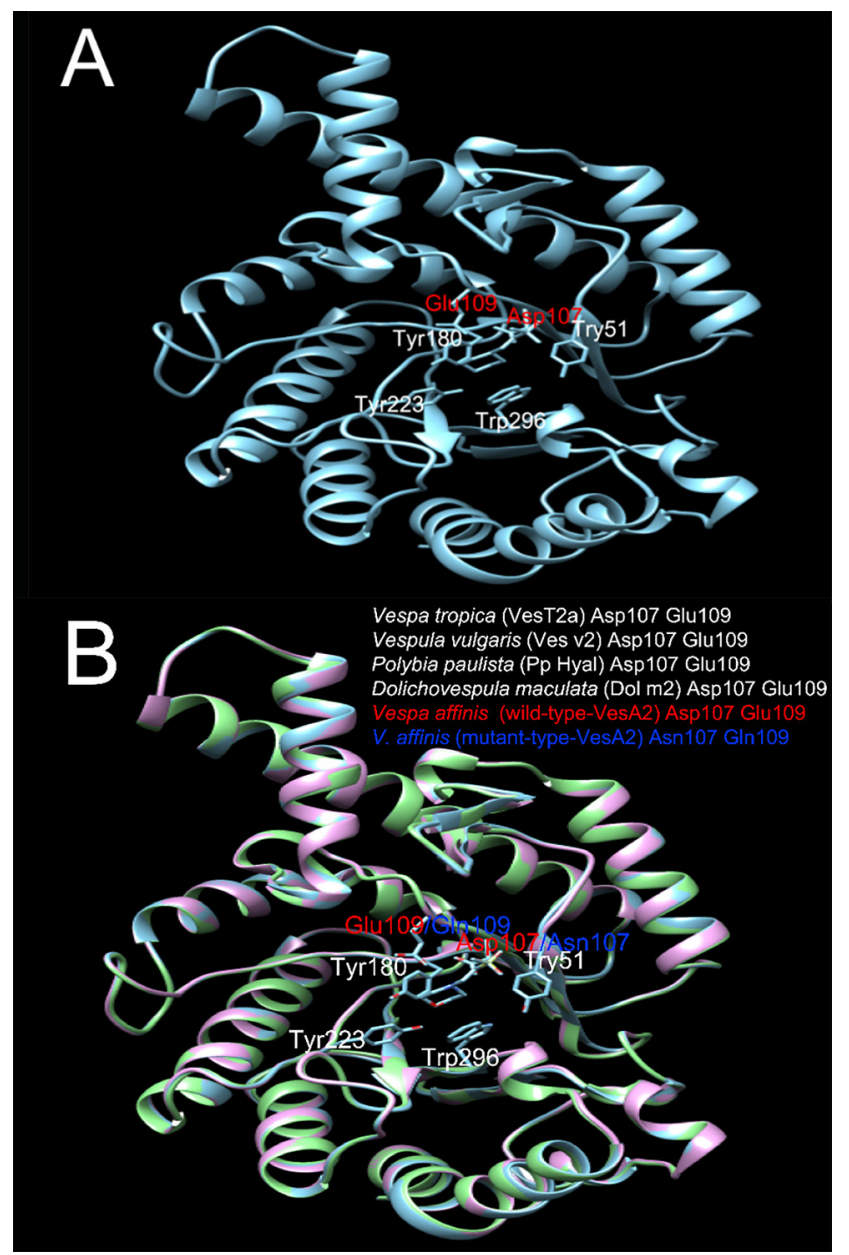

Figure 4. The ribbon representation of the predicted threedimensional structural modelling of VesA2. (A) The structure of wild-type VesA2 (blue ribbon) using Vespula vulgaris venom hyaluronidase (PDB ID: 2ATM) as the template. (B) The superimposition of wild-type VesA2 (blue), mutant VesA2 (green) and 2ATM (Vespula vulgaris venom hyaluronidase, pink ribbon). The catalytic residues in the active sites are indicated (Asp107 and Glu109). The mutant strains contained Asn107 and Gln109. The labels on the top show the catalytic resides of the venom hyaluronidases from the databases.

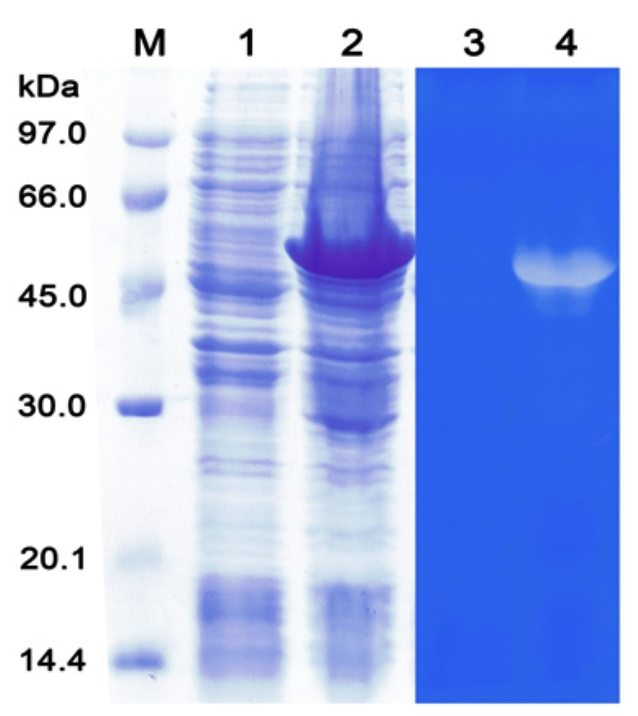

Figure 5. Wild-type recombinant VesA2 (rVesA2) expression in E. coli BL-21 (DE3). Wild-type rVesA2 expression. Lanes 1 and 2 were analyzed by SDS-PAGE, and lanes 3 and 4 were assayed for hyaluronidase activity.

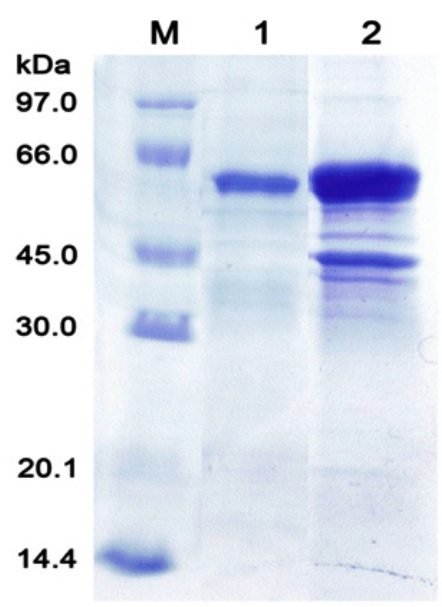

Figure 6. Solubility of wild-type and mutant VesA2. The wildtype $\mathrm{rVes} A 2$ was solubilized in $4 \mathrm{M}$ urea (lane 1 ). The mutant protein was solubilized in 6 M urea (Lane 2)

Table 2. Identification of wild-type and mutant recombinant hyaluronidase (VesA2) of Vespa affinis venom

\begin{tabular}{|c|c|c|c|}
\hline Recombinant protein & Peptide sequences & XC score & Species \\
\hline Wild type & $\begin{array}{l}\text { R.ELTPDQR.I } \\
\text { R.QNWGNMK.I } \\
\text { K.EHPFWNK.K } \\
\text { K.NFSIDLVR.K } \\
\text { R.LFMEETLK.L } \\
\text { R.RELTPDQR.I } \\
\text { R.LFMEETLK.L }\end{array}$ & 426 & Vespa magnifica \\
\hline
\end{tabular}


The mutant protein completely lost its activity from $\mathrm{pH} 2$ to 10 (Figure 7B). The optimal temperature for venom hyaluronidase was $25^{\circ} \mathrm{C}$ but the protein was still active at $60^{\circ} \mathrm{C}$ (Figure $8 \mathrm{~A}$ ). The activity was completely lost after incubation at $70^{\circ} \mathrm{C}$ for 30 mins (data not shown).

\section{Discussion}

Wasp venoms are complex mixtures of biologically active proteins and peptides [5, 21, 25, 26, 40]. Interestingly, Rungsa et al. [27] reported that the antivenoms or inhibitors of the hyaluronidase enzyme increased the venom toxicity. These enzymes are described as spreading factors that facilitate the distribution of other venom components through tissues, causing highly potent and fast acting venom toxicity $[1,20]$. In addition, the high enzymatic activity of these proteins are from crude venom found in the venom gland, which has a low protein quantity. However, the molecular cloning of $V$. affinis hyaluronidase was performed to attempt to produce the recombinant protein, which is similar to that of the natural sources. The gene encoding VesA2 was cloned into E. coli using the pET32a vector. The double Asp107Asn and Glu109Gln mutant protein was prepared. Both the wild-type and mutant proteins were expressed and refolded. The rVesA2 wild-type and mutant proteins were assayed for hyaluronidase activity with a turbidity assay, including evaluating their optimal temperature and optimal $\mathrm{pH}$.

In a previous report, hyaluronidase from the venom of $V$. affinis had a molecular weight of approximately $43 \mathrm{kDa}$ based on 2D-PAGE and LC-MS/MS analysis [26]. The sequence analysis of VesA2 showed a molecular weight of approximately $39.04 \mathrm{kDa}$. The $43-\mathrm{kDa}$ mass protein was $4 \mathrm{kDa}$ higher than the theoretical mass and was predicted to be the result of the carbohydrate moiety attachment. Hymenoptera venom-derived
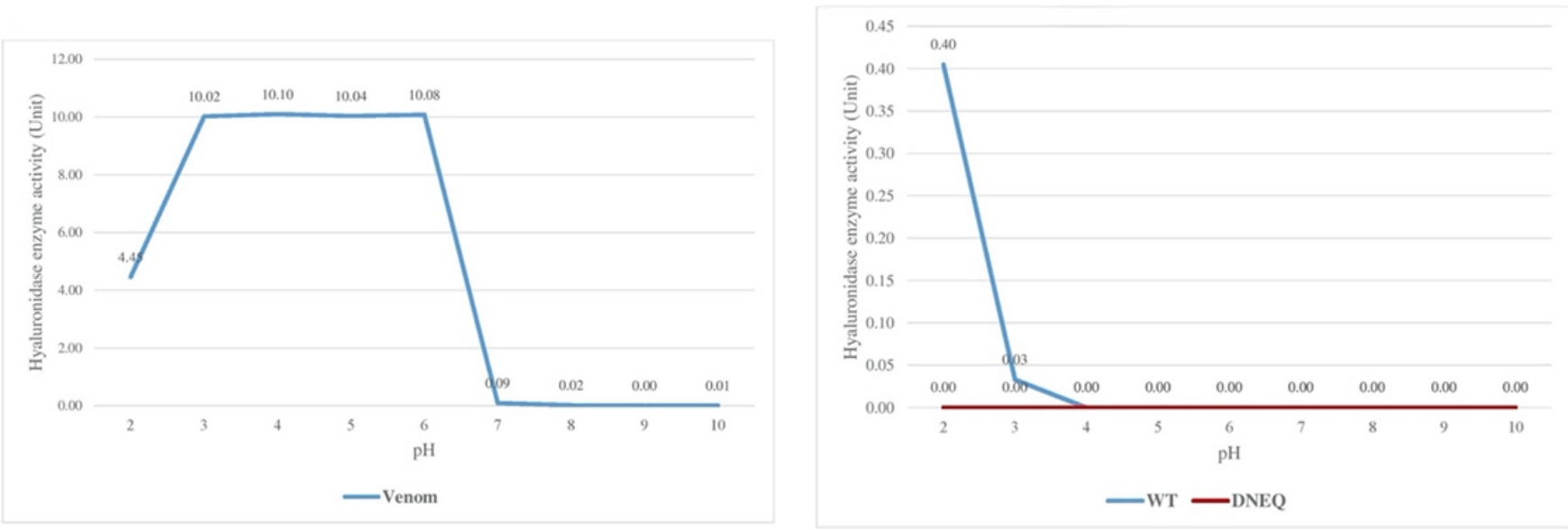

Figure 7. The optimal pH of (A) V. affinis venom hyaluronidase and (B) wild-type and mutant rVesA2. (A) The crude venom showed relatively high hyaluronidase activity at low and neutral $\mathrm{pH}$. (B) The wild-type $\mathrm{rVes} \mathrm{A} 2$ showed activity at $\mathrm{pH}$ 2-3 and completely lost its activity at $\mathrm{pH} 4$ (blue line). The mutant rVesA had no enzymatic activity (red line).
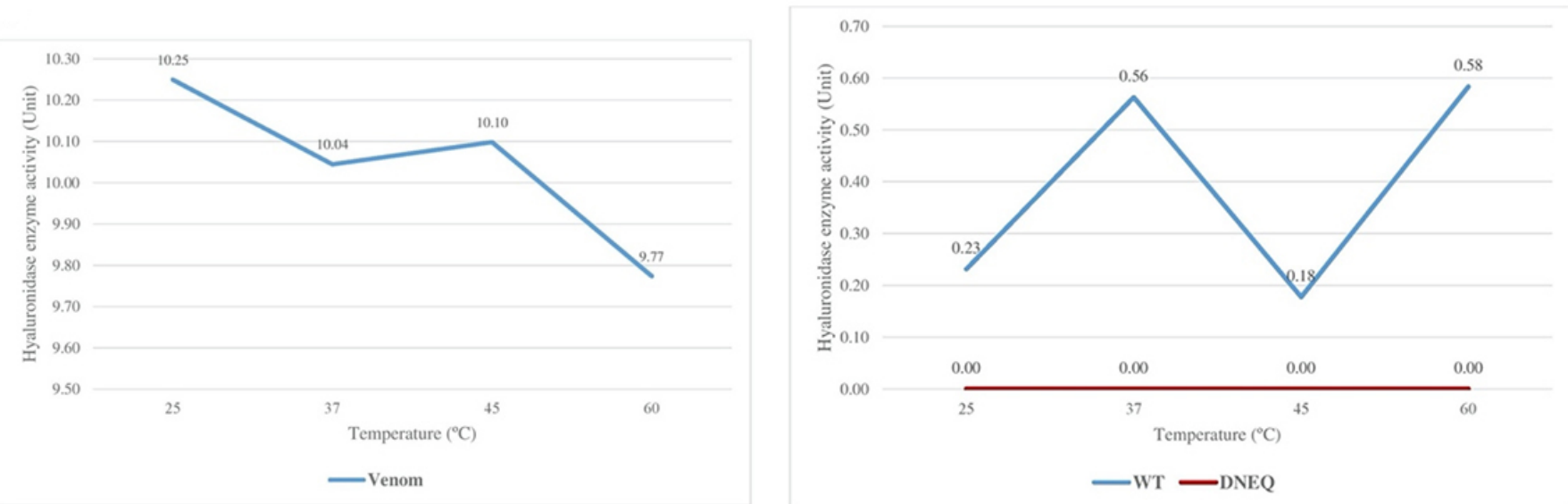

Figure 8. The optimal temperature of (A) V. affinis venom hyaluronidase and (B) wild-type and mutant $\mathbf{r V e s} A 2$. The optimal temperatures were tested in buffer at $\mathrm{pH}$ 2. (A) The crude venom showed high hyaluronidase activity at 25 to $60^{\circ} \mathrm{C}$ and completely lost hyaluronidase activity at $70^{\circ} \mathrm{C}$. (B) The wild-type rVesA2 showed activity at 25 to $60^{\circ} \mathrm{C}$ (blue line). The mutant had no hyaluronidase activity (red line). 
hyaluronidases are always post-translationally glycosylated, which causes extensively higher allergenic properties in the venom $[36,37]$. The cross-reactivity carbohydrate determinant (CCD) contributed the immunogenicity in Hymenoptera venom, such as bee venom or wasp venom $[37,41]$. The Hymenoptera stings represent one of the three major causes of anaphylaxis worldwide [5].

Recombinant Ves $\mathrm{v} 2$, originally from $V$. vulgaris venom, a representative wasp venom hyaluronidase, was modelled and structurally analyzed [36]. Those proteins, including VesA2, were classified in the glycoside hydrolase family 56 (E.C. number 3.2.1.35) [42, 43]. Based on the three-dimensional model structure, VesA2 is composed of seven $\beta$-sheets and seven $\alpha$-helices with a central core $(\alpha / \beta)_{7}[1]$. Four cysteines are the most conserved residues among active venom hyaluronidase since they produce two disulfide bridges that stabilize their three-dimensional structure.

Hymenoptera venom hyaluronidase is relatively conserved, with molecular weights ranging from 33 to $40 \mathrm{kDa}$. The molecular weight of this venom protein was dependent on the CCD to the polypeptides $[44,45]$. These proteins are $N$-glycosylated, which exerts a direct influence on the immunogenicity [41]. The four residues for VesA2 that were $N$-linked were Asn79, Asn99, Asn187 and Asn325. Asn79 and Asn99 corresponded to the native Ves v 2 [36]. Aspartate and glutamate residues commonly serve as the catalytic residues of Hymenoptera hyaluronidase. Marković-Housley et al. [37] reported that Asp111 and Glu113 of bee venom hyaluronidase were proton donors for catalysis. These residues corresponded to Asp107 and Glu109 in many kinds of wasp venom, including Ves $\mathrm{v} 2$ and VesA2 from this study. Aspartate and glutamate act as proton donors, whereas the $N$-acetyl carboxyl groups of the substrate hyaluronic acid (HA) act as nucleophilic bases [37, 46]. Meanwhile, four residues, including tyrosine at position 51, 180, 223 and tryptophan at 296 , are nearby residues that function proximally to the cleavage point of the substrate and are likely in contact with a transition state and/or the released portion of the cleaved HA chain.

Previous studies verified the catalytic residues of wasp venom hyaluronidases using in silico structural analysis. To confirm two catalytic residues (Asp107 and Glu109) using in vitro system, the present work constructed the mutant type of VesA 2 by the double point mutation of Asp107 and Glu109 in order to investigate their individual contributions to the enzymatic activity. The structure of Asn and Gln are basically similar to Asp and Glu, but the R-side chains are converted from acid to the amide groups. The mutant with the double point mutation completely lost its enzymatic activity. These phenomena have been reported previously [46]. The Asn and Gln lack dissociated protons, therefore, are incapable of substitution as general acid/ base [47].

For gene expression, the attempts to obtain a recombinant hyaluronidase from the venom of social Hymenoptera in $E$. coli have been previously reported [12]. These recombinant proteins were not toxic to host cell, because the recombinant fused to a fusion partner in heterologous hosts to neutralize their innate toxicity and increase their expression levels [48]. From gene expression, inclusion bodies in the bacterial system seem unavoidable [49]. This study tried to use the pET32a vector with a thioredoxin (Trx) tag to promote the solubility of protein targets in the cytoplasm of E. coli and facilitate the formation of disulfide bonds [50] However, the wild-type and mutant recombinant VesA2 were expressed in inclusion bodies.

The recombinant protein from Polybia paulista venom was insoluble. However, the recombinant showed a $100 \%$ pattern of cross reactivity with the native protein after detection using specific IgEs from patient sera that recognized the P. paulista venom. These results demonstrated the high degree of sensitivity and specificity of the IgE antibodies to the hyaluronidase allergen. The primary structures of both proteins were unchanged, resulting in a similar secondary structure. This indicates that the venom hyaluronidase may be the primary factor responsible for triggering allergic symptoms that are caused after accidents with this wasp [12]. The primary structure of both proteins has been confirmed by partial amino acid sequence analysis by mass peptide fingerprinting using LC-MS/MS. These proteins exhibited a significantly high homology to venom hyaluronidase from other Hymenoptera, such as V. magnifica, V. tropica and V. affinis [26].

The mutant rVesA2 showed the same percentage of homology to the wild-type because only two nucleotides had been substituted to form a double point mutation. The insoluble protein showed activity on a hyaluronidase zymographic gel [34]. The stepwise reduction of the urea concentration by dialysis was required to recover the enzymatic activity after the activity was assayed with the hyaluronidase turbidimetric method. However, for the mutant rVesA2, the substitution of Asp to Asn and Glu to Gln in the mutant prominently affected the protein activity. The mutant protein completely lost this activity. Asp107 and Glu109 are theoretically the most important catalytic residues in the active site of hyaluronidase.

Venom hyaluronidases are active in a variety of $\mathrm{pH}$ ranges. In 2013, Cavallini et al. [51] classified the enzymes into two groups. The acid hyaluronidases are active in the $\mathrm{pH}$ range from 2 to 4 . The other group, neutral hyaluronidases, are active from pH 5 to 6 [51]. The enzymes in crude venom and recombinant wild-type VesA2 tend to be acid hyaluronidases, and they are active in the most acidic conditions, with a $\mathrm{pH}$ less than 4 . However, the wild-type protein from crude venom tolerated a broader $\mathrm{pH}$ range. This protein was also active in the neutral $\mathrm{pH}$, with activity in a range of $\mathrm{pH} 2$ to 7 . This range was observed for venom hyaluronidase from wasps, including the Thai banded wasp (V. tropica) [27]. In general, the wasp venom hyaluronidase enzymes exhibit maximal enzymatic activity at pH 5-6 [1]. V. affinis venom still has hyaluronidase activity at neutral $\mathrm{pH}$ ( $\mathrm{pH}$ about 7$)$. These results demonstrated that the activity of this wasp venom may act as a spreading factor under normal human physiological conditions, where 
the $\mathrm{pH}$ is near 7.0, which aids in venom toxin diffusion into victim tissues [46, 52-55].

The enzymatic activity of the recombinant wild-type VesA2 decreased rapidly from $\mathrm{pH} 2$ to 3 and completely lost all activity at $\mathrm{pH}$ 4. This indicated that rVesA2 is an extremely active enzyme at strongly acidic $\mathrm{pH}$. For the wildtype rVesA2, although no substitutions had been made, the proteins shifted their optimal $\mathrm{pH}$ from a neutral to an acidic $\mathrm{pH}$. Glycosylation has been identified as a factor responsible not only for increasing protein stability and causing allergenic properties but also for influencing the catalytic activity, $\mathrm{pH}$ optimum and thermal stability of enzymes to different extents [56,57]. The recombinant $E$. coli expression system is non-glycosylating and is mostly used to obtain the highyield recombinant protein that is expressed, which shifts the optimal $\mathrm{pH}$ of rVesA2 to an acidic $\mathrm{pH}$. Otherwise, the activity is decreased at a neutral $\mathrm{pH}$. Therefore, the $\mathrm{pH}$ shift to neutral $\mathrm{pH}$ or basic $\mathrm{pH}$ may result in the loss of hyaluronidase activity in wild-type rVesA2 [58]. However, the optimal temperature of the $V$. affinis venom hyaluronidase was lower than that of other venom hyaluronidases $[1,35]$. These wasps still had $50 \%$ hyaluronidase activity at $37-60^{\circ} \mathrm{C}$, which is usually found in other venom hyaluronidases $[35,55]$.

\section{Conclusion}

Hyaluronidase enzymes are interesting since their application is varied. The enzyme originating from wasp venom was characterized and expressed for further studies. A recombinant $E$. coli-based expression system can be used for up-scale production due to its overexpression capabilities. However, refolding steps are required for the recovery of the enzyme activity. The rVesA2 wild-type enzymes showed the highest activities at a strongly acidic $\mathrm{pH}$, whereas those from crude venom showed high activity at a more neutral $\mathrm{pH}$. The mutant protein, with double point mutations at the catalytic sites, completely loses the enzymatic activity. These characterizations could be useful for any variety of applications.

\section{Abbreviations}

3' RACE: 3' rapid amplification of cDNA ends; 3' UTR: 3' untranslated region; CCD: cross-reactivity carbohydrate determinant; HA: hyaluronic acid; IPTG: isopropyl- $\beta-D-$ thiogalactopyranoside; PCR: polymerase chain reaction; pI: isoelectric point; rVesA2: recombinant Vespa affinis hyaluronidase; Trx: thioredoxin; VesA2: Vespa affinis venom hyaluronidase

\section{Availability of data and materials}

All data generated or analyzed during this study are included in this article.

\section{Funding}

This work was financially supported by (1) the Post-Doctoral Training Program from Research and Technology Transfer Affairs, Khon Kaen University (KKU) and Graduate School, KKU, Thailand (grant no. 583334); (2) KKU Research Fund, fiscal years 2012-2015; (3) Basic Research Grant, Thailand Research Fund (TRF-BRG), years 2014-2016 (BRG5780014).

\section{Competing interests}

The authors declare that they have no competing interests.

\section{Authors' contributions}

PR and PJ conducted most of the experiments, coordinated the data analysis and drafted the manuscript. YS carried out partial molecular biology techniques. NJ performed the bioinformatics analysis. SK, RP and NU contributed to the study design and editing manuscript. JD performed the molecular analyses and contributed to the editing of the manuscript. SD designed the research and the experiments, coordinated the study, wrote and edited the manuscript. All authors read and approved the final manuscript.

\section{Ethics approval}

The present study was approved by the Animal Ethics Committee of Khon Kaen University based on the Ethics for Animal Experimentation of the National Research Council of Thailand (Reference. 0514.1.12.2/1).

\section{Consent for publication}

Not applicable.

\section{References}

1. Girish KS, Kemparaju K. The magic glue hyaluronan and its eraser hyaluronidase: a biological overview. Life Sci. 2007 May 1;80(21):1921-43.

2. Volfova V, Hostomska J, Cerny M, Votypka J, Volf P. Hyaluronidase of bloodsucking insects and its enhancing effect on leishmania infection in mice. PLoS Negl Trop Dis. 2008 Sep 17;2(9):e294.

3. Almaaytah $A$, Albalas $Q$. Scorpion venom peptides with no disulfide bridges: a review. Peptides. 2014 Jan;51:35-45.

4. Bazon ML, Perez-Riverol A, dos Santos-Pinto JRA, Fernandes LGR, Lasa AM, Justo-Jacomini DL, et al. Heterologous expression, purification and immunoreactivity of the Antigen 5 from Polybia paulista wasp venom. Toxins (Basel). 2017 Sep;9(9):259.

5. Perez-Riverol A, dos Santos-Pinto JRA, Lasa AM, Palma MS, BrochettoBraga MR. Wasp venomic: Unravelling the toxins arsenal of Polybia paulista venom and its potential pharmaceutical applications. J Proteomics. 2017 May 24;161:88-103.

6. de Souza BM, da Silva AV, Resende VM, Arcuri HA, dos Santos Cabrera MP, Ruggiero Neto J, et al. Characterization of two novel polyfunctional mastoparan peptides from the venom of the social wasp Polybia paulista. Peptides. 2009 Aug;30(8):1387-95.

7. Henriksen A, King TP, Mirza O, Monsalve RI, Meno K, Ipsen H, et al. Major venom allergen of yellow jackets, Ves $\vee 5$ : structural characterization of a pathogenesis-related protein superfamily. Proteins. 2001 Dec 1;45(4):438-48. 
8. Yang $X$, Wang $Y$, Lee WH, Zhang Y. Antimicrobial peptides from the venom gland of the social wasp Vespa tropica. Toxicon. 2013 Nov;74:151-7.

9. Magalhães MR, da Silva NJJr, Ulhoa CJ. A hyaluronidase from Potamotrygon motoro (freshwater stingrays) venom: isolation and characterization. Toxicon. 2008 May;51(6):1060-7.

10. Xia X, Liu R, Li Y, Xue S, Liu Q, Jiang X, et al. Cloning and molecular characterization of scorpion Buthus martensi venom hyaluronidases: a novel full-length and diversiform noncoding isoforms. Gene. $2014 \mathrm{Sep}$ 1;547(2):338-45.

11. Kaneiwa T, Mizumoto S, Sugahara K, Yamada S. Identification of human hyaluronidase- 4 as a novel chondroitin sulfate hydrolase that preferentially cleaves the galactosaminidic linkage in the trisulfated tetrasaccharide sequence. Glycobiology. 2010 Mar;20 (3):300-9.

12. Justo Jacomini DL, Gomes Moreira SM, Campos Pereira FD, Zollner Rde L, Brochetto Braga MR. Reactivity of IgE to the allergen hyaluronidase from Polybia paulista (Hymenoptera, Vespidae) venom. Toxicon. 2014 May;82:104-11.

13. Rodríguez-Rios L, Díaz-Peña LF, Lazcano-Pérez F, Arreguín-Espinosa R, Rojas-Molina A, García-Arredondo A. Hyaluronidase-like enzymes are a frequent component of venoms from theraphosid spiders. Toxicon. 2017 Sep 15;136:34-43.

14. Barth T, Mandacaru SC, Charneau S, Souza MV, Ricart CAO, Noronha $\mathrm{EF}$, et al. Biochemical and structural characterization of a protein complex containing a hyaluronidase and a CRISP-like protein isolated from the venom of the spider Acanthoscurria natalensis. J Proteomics. 2019 Feb 10;192:102-13.

15. Cid-Uribe JI, Santibáñez-López CE, Meneses EP, Batista CVF, JiménezVargas JM, Ortiz E, et al. The diversity of venom components of the scorpion species Paravaejovis schwenkmeyeri (Scorpiones: Vaejovidae) revealed by transcriptome and proteome analyses. Toxicon. $2018 \mathrm{Sep}$ 1;151:47-62.

16. Batista CV, Roman-Gonzalez SA, Salas-Castillo SP, Zamudio FZ, GomezLagunas F, Possani LD. Proteomic analysis of the venom from the scorpion Tityus stigmurus: biochemical and physiological comparison with other Tityus species. Comp Biochem Physiol C Toxicol Pharmacol. 2007 JulAug;146(1-2):147-57.

17. Möller C, Vanderweit N, Bubis J, Marí F. Comparative analysis of proteases in the injected and dissected venom of cone snail species. Toxicon. 2013 Apr;65:59-67.

18. Wiezel GA, dos Santos PK, Cordeiro FA, Bordon KC, Selistre-de-Araújo $\mathrm{HS}$, Ueberheide $B$, et al. Identification of hyaluronidase and phospholipase $B$ in Lachesis muta rhombeata venom. Toxicon. 2015 Dec 1;107(Pt B):359-68.

19. Girish KS, Mohanakumari HP, Nagaraju S, Vishwanath BS, Kemparaju $K$. Hyaluronidase and protease activities from Indian snake venoms: neutralization by Mimosa pudica root extract. Fitoterapia. 2004 Jun;75(34):378-80.

20. Girish KS, Shashidharamurthy R, Nagaraju S, Gowda TV, Kemparaju K. Isolation and characterization of hyaluronidase a "spreading factor" from Indian cobra (Naja naja) venom. Biochimie. 2004 Mar;86(3):193-202.

21. Justo Jacomini DL, Campos Pereira FD, Aparecido dos Santos Pinto JR, dos Santos LD, da Silva Neto AJ, Giratto DT, et al. Hyaluronidase from the venom of the social wasp Polybia paulista (Hymenoptera, Vespidae): Cloning, structural modeling, purification, and immunological analysis. Toxicon. 2013 Mar 15;64:70-80.

22. Kularatne SA, Gawarammana IB, de Silva PH. Severe multi-organ dysfunction following multiple wasp (Vespa affınis) stings. Ceylon Med J. 2003 Dec;48(4):146-7.

23. Das RN, Mukherjee K. Asian wasp envenomation and acute renal failure: a report of two cases. Mcgill J Med. 2008 Jan;11(1):25-8.

24. Sookrung $N$, Wong-Din-Dam S, Tungtrongchitr A, Reamtong $O$, Indrawattana N, Sakolvaree Y, et al. Proteome and allergenome of Asian wasp, Vespa affinis, venom and IgE reactivity of the venom components. J Proteome Res. 2014 Mar 7;13(3):1336-44.

25. Sukprasert S, Rungsa P, Uawonggul N, Incamnoi $P$, Thammasirirak $S$, Daduang J, et al. Purification and structural characterisation of phospholipase A1 (Vespapase, Ves a 1) from Thai banded tiger wasp (Vespa affinis) venom. Toxicon. 2013 Jan;61:151-64.
26. Rungsa P, Incamnoi P, Sukprasert S, Uawonggul N, Klaynongsruang $S$, Daduang J, et al. Comparative proteomic analysis of two wasps venom, Vespa tropica and Vespa affınis. Toxicon. 2016 Sep 1;119:159-67.

27. Rungsa P, Incamnoi P, Sukprasert S, Uawonggul N, Klaynongsruang S, Daduang J, et al. Cloning, structural modelling and characterization of VesT2s, a wasp venom hyaluronidase (HAase) from Vespa tropica. J Venom Anim Toxins incl Trop Dis. 2016 Oct 22;22:28. doi: 10.1186/ s40409-016-0084-5.

28. Oliveira-Mendes BBR, Miranda SEM, Sales-Medina DF, Magalhaes BF, Kalapothakis Y, Souza RP, et al. Inhibition of Tityus serrulatus venom hyaluronidase affects venom biodistribution. PLoS Negl Trop Dis. 2019 Apr 19;13(4):e0007048.

29. Rungsa P, Peigneur S, Daduang S, Tytgat J. Purification and biochemical characterization of VesT1s, a novel phospholipase A1 isoform isolated from the venom of the greater banded wasp Vespa tropica. Toxicon. 2018 Jun 15;148:74-84.

30. Janpan P, Saengkun Y, Rungsa P, Vesaratchavest $M$, Upathanpreecha T, Tastub P, et al. Comparative of recombinant Vespa affinis hyaluronidase expressed in different cloning vector and their biological properties. Int J Appl Phys Sci. 2018;4(2):38-44.

31. Incamnoi P, Patramanon R, Thammasirirak S, Chaveerach A, Uawonggul $\mathrm{N}$, Sukprasert $\mathrm{S}$, et al. Heteromtoxin $(\mathrm{HmTx})$, a novel heterodimeric phospholipase A2 from Heterometrus laoticus scorpion venom. Toxicon. 2013 Jan;61:62-71.

32. Ubonbal R, Posoongnoen S, Daduang J, Klaynongsruang S, Daduang $\mathrm{S}$. Amino acid sequence of amylase type alpha, Mlamy, from ok-rong mango (Mangifera indica Linn. cv. Ok-Rong). Am J Biochem Biotechnol. 2015 Mar 11;(3):119-26.

33. Wäneskog M, Bjerling P. Multi-fragment site-directed mutagenic overlap extension polymerase chain reaction as a competitive alternative to the enzymatic assembly method. Anal Biochem. 2014 Jan 1;444:32-7.

34. Mio K, Stern R. Reverse hyaluronan substrate gel zymography procedure for the detection of hyaluronidase inhibitors. Glycoconj J. 2000 Nov;17(11):761-6.

35. Feng L, Gao R, Gopalakrishnakone P. Isolation and characterization of a hyaluronidase from the venom of Chinese red scorpion Buthus martensi. Comp Biochem Physiol. Toxicol Pharmacol. 2008 Jul 7;148(3):250-7.

36. Skov LK, Seppala U, Coen JJ, Crickmore N, King TP, Monsalve R, et al. Structure of recombinant Ves $\vee 2$ at 2.0 Angstrom resolution: structural analysis of an allergenic hyaluronidase from wasp venom. Acta Crystallogr D Biol Crystallogr. 2006 Jun;62(Pt 6):595-604..

37. Marković-Housley Z, Miglierini G, Soldatova L, Rizkallah PJ, Müller U, Schirmer T. Crystal structure of hyaluronidase, a major allergen of bee venom. Structure. 2000 Oct 15;8(10):1025-35.

38. Padavattan, S, Schirmer T, Schmidt M, Akdis C, Valenta R, Mittermann I, et al. Identification of a B-cell epitope of hyaluronidase, a major bee venom allergen, from its crystal structure in complex with a specific Fab. J Mol Biol. 2007 May 4;368(3):742-52.

39. Srisong H, Sukprasert S, Klaynongsruang S, Daduang J, Daduang S. Identification, expression and characterization of the recombinant Sol $g$ 4.1 protein from the venom of the tropical fire ant Solenopsis geminata. J Venom Anim Toxins incl Trop Dis. 2018 Aug 29;24:23. doi: 10.1186/ s40409-018-0159-6.

40. Perez-Riverol A, Campos Pereira FD, Musacchio Lasa A, Romani Fernandes LG, Santos-Pinto JR, Justo-Jacomini DL, et al. Molecular cloning, expression and IgE-immunoreactivity of phospholipase A1, a major allergen from Polybia paulista (Hymenoptera: Vespidae) venom. Toxicon. 2016 Dec 15;124:44-52.

41. Seppälä U, SelbyD, Monsalve R, King TP, Ebner C, Roepstorff P, et al. Structural and immunological characterization of the $N$-glycans from the major yellow jacket allergen Ves $\vee 2$ : The $N$-glycan structures are needed for the human antibody recognition. Mol Immunol. 2009 Jun;46(10):2014-21.

42. Bordon KC, Wiezel GA, Amorim FG, Arantes EC. Arthropod venom Hyaluronidases: biochemical properties and potential applications in medicine and biotechnology. J Venom Anim Toxins Incl Trop Dis. 2015 Oct 22;21:43.

43. dos Santos-Pinto JRA, Perez-Riverol A, Lasa AM, Palma MS. Diversity of peptidic and proteinaceous toxins from social Hymenoptera venoms. Toxicon. 2018 Jun 15;148:172-96. 
44. Pinto JR, Santos LD, Arcuri HA, Dias NB, Palma MS. Proteomic characterization of the hyaluronidase (E.C. 3.2.1.35) from the venom of the social wasp Polybia paulista. Protein Peptide Lett. 2012 19;(6):625-35.

45. Kubelka V, Altmann F, März L. The asparagine-linked carbohydrate of honeybee venom hyaluronidase. Glycoconj J. 1995 Feb;12(1):77-83.

46. Arming S, Strobl B, Wechselberger C, Kreil G. In vitro mutagenesis of $\mathrm{PH}-20$ hyaluronidase from human sperm. Eur J Biochem. 1997 Aug 1;247(3):810-4.

47. Zhang L, Bharadwaj AG, Casper A, Barkley J, Barycki JJ, Simpson MA. Hyaluronidase activity of human Hyal1 requires active site acidic and tyrosine residues. J Biol Chem. 2009 Apr 3;284(14):9433-42.

48. Zhou L, Zhao Z, Li B, Cai Y, Zhang S. TrxA mediating fusion expression of antimicrobial peptide CM4 from multiple joined genes in Escherichia coli. Protein Expr Purif. 2009 Apr;64(2):225-30.

49. Singh SM, Panda AK. Solubilization and refolding of bacterial inclusion body proteins. J Biosci Bioeng. 2005 Apr;99(4):303-10.

50. Stewart EJ, Aslund F, Beckwith J. Disulfide bond formation in the Escherichia coli cytoplasm: an in vivo role reversal for the thioredoxins. EMBO J. 1998 Oct 1;17(19):5543-50.

51. Cavallini M, Gazzola R, Metalla M, Vaienti L. The role of Hyaluronidase in the treatment of complications from hyaluronic acid dermal fillers. Aesthet Surg J. 2013 Nov 1;33(8):1167-74.

52. Amorim FG, Boldrini-França J, de Castro Figueiredo Bordon K, Cardoso IA, De Pauw E, Quinton L, et al. Heterologous expression of rTsHyal-1: the first recombinant hyaluronidase of scorpion venom produced in Pichia pastoris system. Appl Microbiol Biotechnol. 2018 Apr;102(7):3145-58.

53. Lambers H, Piessens S, Bloem A, Pronk H, Finkel P. Natural skin surface $\mathrm{pH}$ is on average below 5 , which is beneficial for its resident flora. Int J Cosmet Sci. 2006 Oct;28(5):359-70.

54. Pukrittayakamee S, Warrell DA, Desakorn V, McMichael AJ, White NJ, Bunnag D. The hyaluronidase activities of some Southeast Asian snake venoms. Toxicon. 1988;26(7):629-37.

55. Wahby AF, Mahdy el-SM, El-Mezayen HA, Salama WH, Abdel-Aty AM, Fahmy AS. Egyptian horned viper Cerastes cerastes venom hyaluronidase: purification, partial characterization and evidence for its action as a spreading factor. Toxicon. 2012 Dec 15;60(8):1380-9.

56. Nakamura T, Zámocký $M$, Zdráhal Z, Chaloupková R, Monincová M, Prokop Z, et al. Expression of glycosylated haloalkane dehalogenase LinB in Pichia pastoris. Protein Protein Expr Purif. 2006 Mar;46(1):85-91.

57. Rodriguez E1, Wood ZA, Karplus PA, Lei XG. Site-directed mutagenesis improves catalytic efficiency and thermostability of Escherichia coli $\mathrm{pH}$ 2.5 acid phosphatase/phytase expressed in Pichia pastoris. Arch Biochem Biophys. 2000 Oct 1;382(1):105-12.

58. Chahed H, Boumaiza M, Ezzine A, Marzouki MN. Heterologous expression and biochemical characterization of a novel thermostable Sclerotinia sclerotiorum GH45 endoglucanase in Pichia pastoris. Int J Biol Macromol. 2018 Jan;106:629-35. 